\title{
Crystal Structure, Spectroscopy, SEM Analysis, and Computational Studies of $N$-(1,3-Dioxoisoindolin-2yl)benzamide
}

\author{
Hakan Bülbül, ${ }^{1}$ Yavuz Köysal, ${ }^{2}$ Necmi Dege, ${ }^{1}$ Sümeyye Gümüiş, ${ }^{3}$ and Erbil Ağar ${ }^{3}$ \\ ${ }^{1}$ Department of Physics, Faculty of Arts and Sciences, Ondokuz Mayıs University, 55139 Samsun, Turkey \\ ${ }^{2}$ Yeşilyurt Demir Çelik Vocational School, Ondokuz Mayıs University, 55300 Samsun, Turkey \\ ${ }^{3}$ Department of Chemistry, Faculty of Arts and Sciences, Ondokuz Mayıs University, 55139 Samsun, Turkey
}

Correspondence should be addressed to Hakan Bülbül; hbulbul@omu.edu.tr

Received 9 May 2015; Revised 29 July 2015; Accepted 16 August 2015

Academic Editor: Paul R. Raithby

Copyright (C) 2015 Hakan Bülbül et al. This is an open access article distributed under the Creative Commons Attribution License, which permits unrestricted use, distribution, and reproduction in any medium, provided the original work is properly cited.

\begin{abstract}
The compound $\mathrm{N}$-(1,3-dioxoisoindolin-2yl)benzamide, $\mathrm{C}_{15} \mathrm{H}_{10} \mathrm{~N}_{2} \mathrm{O}_{3}$, was prepared by the heating of an ethanolic solution of 2hydroxy- $1 H$-isoindole-1,3(2H)-dione and 4-chloroaniline. The product was characterised using a combination of IR spectroscopy, SEM, and single crystal X-ray diffraction techniques. In addition to the experimental analysis, theoretical calculations were used to investigate the crystal structure in order to compare experimental and theoretical values. The X-ray diffraction analysis shows that the compound crystallises in the monoclinic space group $P 2_{1} / c$ with the geometric parameters of $a=13.5324(11) \AA, b=$ 9.8982(8) $\AA, c=9.7080(8) \AA$, and $\beta=95.425(6)^{\circ}$. The crystal structure is held together by a network of $\mathrm{N}-\mathrm{H} \cdots \mathrm{O}$ hydrogen bonds involving the carboxamide group.
\end{abstract}

\section{Introduction}

The molecular structure of $N$-(1,3-dioxoisoindolin-2yl)benzamide contains isoindoline and benzamide moieties. Benzamide groups show various pharmaceutical activities including antiemetic, antipsychotic, and antiarrythmic [1], antiinflammatory, immunomodulatory, antitumoral, and antiallergic activities [2] and are also known to have important bioactive frameworks [3]. Isoindoline derivatives show antiinflammatory, antipsychotic, antileukemic, antiviral, and antiulcer properties [4-6]. It is reported that disubstituted isoindolines display antibacterial, diuretic, and antitumor activity. Isoindolines, substituted with carboxylic acid groups, have been employed in SAR studies and also as candidates for organic light emitting diodes [7]. As a part of our ongoing research on benzamide and isoindoline derivatives, the title compound was synthesized and characterized by various methods.

\section{Experimental}

2.1. Synthesis and Crystallization. The compound $N$-(1,3dioxoisoindolin-2yl)benzamide (Scheme 1) was prepared by a refluxing mixture of a solution containing 2-hydroxy$1 \mathrm{H}$-isoindole-1,3(2H)-dione $(0.0095 \mathrm{~g} 0.058 \mathrm{mmol})$ in $20 \mathrm{~mL}$ ethanol and a solution containing 4-chloroaniline $(0.0158 \mathrm{~g}$ $0.116 \mathrm{mmol})$ in $20 \mathrm{~mL}$ ethanol. The reaction mixture was stirred for $1 \mathrm{~h}$ under reflux. The crystals of $N$-(1,3-dioxoisoindolin-2yl) benzamide suitable for X-ray analysis were obtained from ethylalcohol by slow evaporation (yield 53\%; $\mathrm{m} \cdot \mathrm{p}=471-479 \mathrm{~K})$.

2.2. Refinement. Data collection of the title compound, $\mathrm{C}_{15} \mathrm{H}_{10} \mathrm{~N}_{2} \mathrm{O}_{3}$, was performed with STOE IPDS II single crystal X-ray diffractometer using graphite monochromated MoK $\alpha$ radiation $(\lambda=0.71073 \AA)$ at room temperature (293 K). Cell parameters were obtained by using X-AREA [8] and data reduction was achieved with X-RED32 [8] software. 


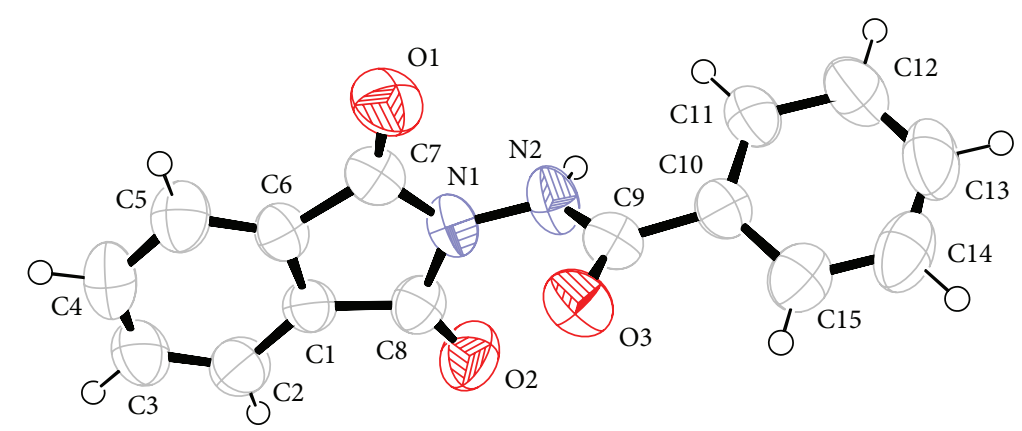

FIgURE 1: Asymmetric unit of $\mathrm{C}_{15} \mathrm{H}_{10} \mathrm{~N}_{2} \mathrm{O}_{3}$ (50\% probability displacement ellipsoids).

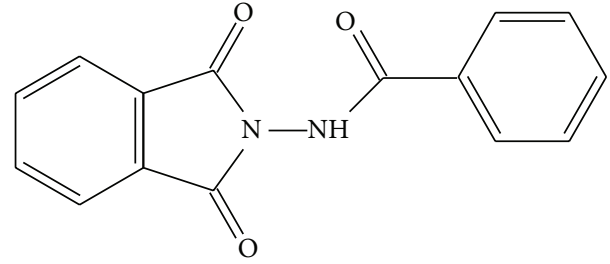

Scheme 1: Chemical diagram of title compound.

In total, 12087 reflections were collected with angles in the range $2.55^{\circ}<\theta<27.66^{\circ}$ using the $\omega$ scan mode. The structure was solved and refined with SHELXS97 [9] and SHELXL97 [9] software. Molecular graphics were created using ORTEP-3 [10]. WinGX [11] was used to prepare the data for publication.

All nonhydrogen atoms were refined anisotropically. The carboxamide hydrogen atom (H2A), bonded to (N2), was located in the Fourier difference map and refined isotropically. All other $\mathrm{H}$ atoms were placed geometrically and refined with their parent atoms with usable riding model $[\mathrm{C}-\mathrm{H}=$ $0.93 \AA$ for aromatic ring, $\left.U_{\text {iso }}(\mathrm{H})=1.2 U_{\mathrm{eq}}(\mathrm{C})\right]$. The details of the experimental and refinement process are shown in Table 1.

\section{Results and Discussion}

3.1. Crystal Structure Description. The location the hydrogen atom on the N2 atom confirms that the structure adopts the amide form rather than the enolic form (Figure 1). The amide links the dioxoisoindolin and arene groups. The individual aromatic rings in structure are essentially planar. The fused isoindoline ring is perfectly planar with a maximum deviation of $0.018(2) \AA$ for $\mathrm{C} 8$, while the arene ring $(\mathrm{C} 10-\mathrm{C} 15)$ is also planar with a maximum deviation of -0.007 (4) $\AA$ for C13. The fused isoindoline ring makes a dihedral angle of 65.45 $(7)^{\circ}$ to the arene ring. The bond parameters in the structure are closely related to values in closely related structures [1214]. The torsion angle C10-C9-N2-N1 is $179.68(18)^{\circ}$ which confirms that the side chain conformation of the molecule is defined as the anticonformation. The independent molecules within the crystal are linked by $\mathrm{N}-\mathrm{H}$... O hydrogen bonds [N2-H2A … O3 with symmetry code (i): $x,-y+1 / 2, z+1 / 2$ ] that generate $\mathrm{C} 4$ motif [15] which links the molecules infinite
TABLE 1: Experimental details of $\mathrm{C}_{15} \mathrm{H}_{10} \mathrm{~N}_{2} \mathrm{O}_{3}$.

\begin{tabular}{|c|c|}
\hline Crystal data & \\
\hline Empirical formula & $\mathrm{C}_{15} \mathrm{H}_{10} \mathrm{~N}_{2} \mathrm{O}_{3}$ \\
\hline Formula weight & 266.25 \\
\hline Colour, habit & Colorless, plate \\
\hline Crystal dimensions (mm) & $0.76 \times 0.35 \times 0.08$ \\
\hline Crystal system & Monoclinic \\
\hline Space group & $P 2_{1} / c$ \\
\hline$Z$ & 4 \\
\hline$a(\AA), b(\AA), c(\AA)$ & $13.5324(11), 9.8982(8), 9.7080(8)$ \\
\hline$\beta\left(^{\circ}\right)$ & $95.425(6)$ \\
\hline Collection ranges & $\begin{array}{l}-16 \leq h \leq 16 ;-12 \leq k \leq 12 ; \\
-12 \leq l \leq 12\end{array}$ \\
\hline Temperature (K) & 293 \\
\hline Volume $\left(\AA^{3}\right)$ & $1294.53(18)$ \\
\hline$D_{x}\left(\mathrm{Mg} \mathrm{m}^{-3}\right)$ & 1.366 \\
\hline Radiation type & $\operatorname{Mo} K \alpha(\lambda=0.71073 \AA)$ \\
\hline $\begin{array}{l}\text { Absorption coefficient } \mu \\
\left(\mathrm{mm}^{-1}\right)\end{array}$ & 0.10 \\
\hline Absorption correction & Integration \\
\hline$T_{\max }, T_{\min }$ & $0.9909-0.9525$ \\
\hline$F(000)$ & 552 \\
\hline$\theta$ range for data collection $\left({ }^{\circ}\right)$ & $2.55-27.66$ \\
\hline Independent reflections & $1822\left(R_{\mathrm{int}}=0.113\right)$ \\
\hline Data/restraints/parameters & $2682 / 0 / 185$ \\
\hline Goodness-on-fit on $F^{2}$ & 1.105 \\
\hline $\begin{array}{l}\text { Number of measured, } \\
\text { independent, and observed } \\
{[I>2 \sigma(I)] \text { reflections }}\end{array}$ & $12087,2682,1822$ \\
\hline$R\left[F^{2}>2 \sigma\left(F^{2}\right)\right], w R\left(F^{2}\right), S$ & $0.065,0.116,1.11$ \\
\hline $\begin{array}{l}\text { Largest diff. peak and hole } \\
\left(\mathrm{e} \AA^{-3}\right)\end{array}$ & 0.23 and -0.21 \\
\hline CCDC & 1056467 \\
\hline
\end{tabular}

chain along the $c$ axis (Figure 2). The detail of the hydrogen bond is shown in Table 2 .

3.2. Computational Methods. In order to obtain the most optimized geometry, theoretical calculations were performed 


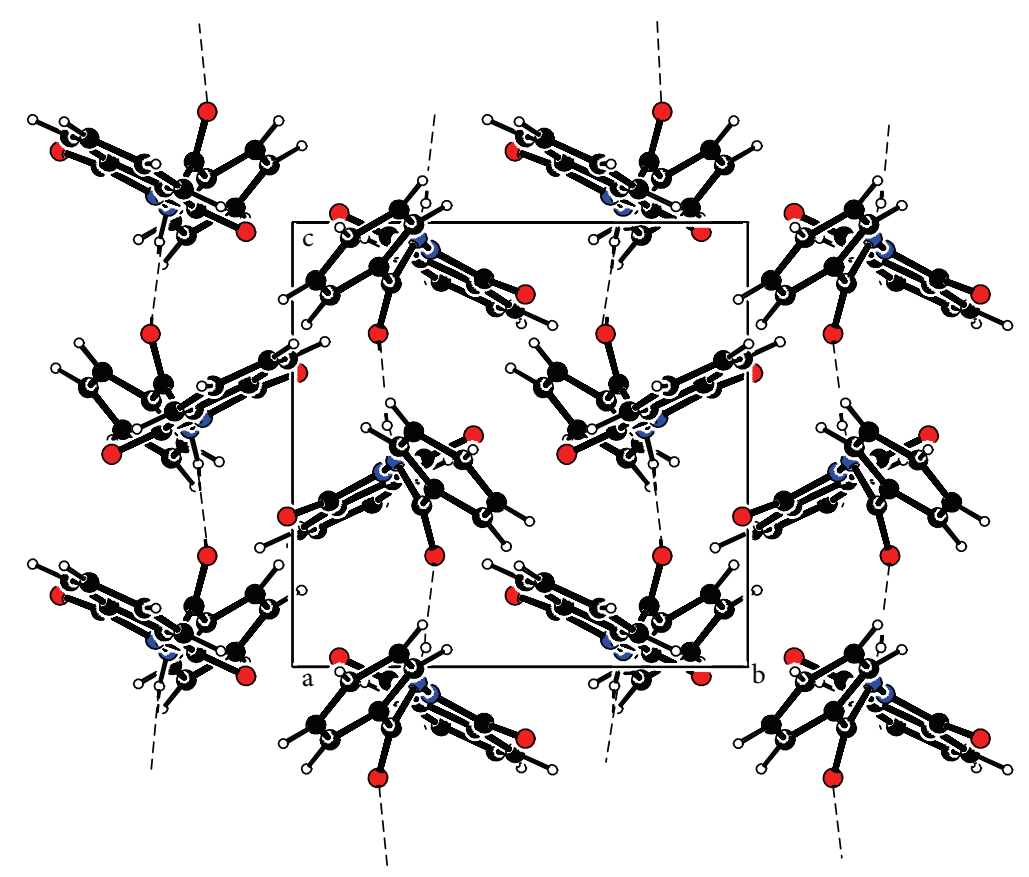

Figure 2: The crystal packing of the compound viewed down the $c$-axis.

TABLE 2: Hydrogen-bond geometry of $\mathrm{C}_{15} \mathrm{H}_{10} \mathrm{~N}_{2} \mathrm{O}_{3}\left(\AA,^{\circ}\right)$.

\begin{tabular}{lcccc}
\hline $\mathrm{D}-\mathrm{H} \cdots \mathrm{A}$ & $\mathrm{D}-\mathrm{H}$ & $\mathrm{H} \cdots \mathrm{A}$ & $\mathrm{D} \cdots \mathrm{A}$ & $\mathrm{D}-\mathrm{H} \cdots \mathrm{A}$ \\
\hline $\mathrm{N} 2-\mathrm{H} 2 \mathrm{~A} \cdots \mathrm{O}^{\mathrm{i}}$ & $0.89(2)$ & $1.99(2)$ & $2.802(2)$ & $151.3(19)$ \\
\hline
\end{tabular}

with ab initio HF and DFT(B3LYP) method by using the standard basis set of $6-31+G(d)[16-19]$ in the Gaussian03 software package [20] and Gaussview4.1 visualization program [21].

\subsection{Optimized Geometry. The total energy of the title com-} pound was calculated using the B3LYP/6-31+G(d) which is (-912,84239530 a.u.) lower than that calculated by the HF/631+G(d) method (-907.39330891 a.u.). Selected optimized parameters (bond lengths, bond angles, and torsion angles) are listed in Table 3 with related experimental and theoretical values. All of these optimized parameters are obtained from experimental $\mathrm{X}$-ray analysis and theoretically calculated by $\mathrm{HF} / 6-31+\mathrm{G}(\mathrm{d})$ and B3LYP/6-31+G (d) methods. It is seen that obtained optimized parameters show a good approximation with X-ray results. But some of these optimized parameters are somewhat different from experimental values. It is because the theoretical calculations are made for isolated molecules in gaseous phase while experimental results are based on solid phase of the molecule [22, 23]. The most notable discrepancy occurs at C8-N1-N2-C9 torsion angle $\left(-91.2(3)^{\circ}\right.$ for $\mathrm{X}$-ray, $-74.3417^{\circ}$ for DFT, and $-72.6382^{\circ}$ for $\mathrm{HF}$ ) which is partially involved in the hydrogen bond. It can be considered that intermolecular interaction affects the crystal system. The bridged $\mathrm{C} 10-\mathrm{C} 9-\mathrm{N} 2-\mathrm{N} 1$ torsion angle was obtained as $179.68(18)^{\circ}$ for X-ray results. This torsion angle has been calculated as $174.620^{\circ}$ and $174.582^{\circ}$ for DFT and HF levels, respectively. Root-mean-square-error (RMSE) was obtained with selected theoretical values. Calculated RMSE for selected bond lengths and bond angles are $0,0198 \AA, 0,606^{\circ}$ for B3LYP/6-31+G(d) level, and $0,0145 \AA$, $0,753^{\circ}$ for $\mathrm{HF} / 6$ $31+\mathrm{G}(\mathrm{d})$ level, respectively. As a result of these calculations, it can be interpreted that B3LYP/6-31+G(d) level is giving more consistent results with $\mathrm{X}$-ray experimental values.

3.4. Molecular Electrostatic Potential (MEP). To illustrate the charge distribution of the title compound, the molecular electrostatic potential (MEP) was investigated by B3YLP function theory with the standard basis set of $6-31+G(d)$. Electrostatic potential, $V(r)$, that is formed by nuclei and electrons of the system at given point $(r)$ is defined as [24]

$$
V(\mathbf{r})=\sum_{A} \frac{Z_{A}}{\left|\mathbf{R}_{A}-\mathbf{r}\right|}-\int \frac{\rho\left(\mathbf{r}^{\prime}\right) d \mathbf{r}^{\prime}}{\left|\mathbf{r}^{\prime}-\mathbf{r}\right|}
$$

where $Z_{A}$ is the charge of nucleus $A$ that is located at $R_{A}, \rho\left(r^{\prime}\right)$ is electron density function of molecule, and $r^{\prime}$ is the dummy integration variable. Molecular electrostatic potential (MEP) gives information of electrophilic attack and nucleophilic reactions besides hydrogen bonding interactions [25-28]. To interpret the molecular electrostatic potential (MEP) easily, a colored spectrum was used. From this spectrum the blue regions indicate positive molecular electrostatic potentials which are the preferred sites for nucleophilic attack while the red regions indicate negative molecular electrostatic potentials which are the preferred sites for electrophilic attack. As seen from Figure 3, the negative regions were mainly condensed on $\mathrm{O}$ atoms of the molecule with the maximum value of $-0.053 \mathrm{a}$.u. for atom $\mathrm{O} 3$ whereas positive regions were localized on N2-H2A bond of the amide group in the studied molecule with maximum value of 0.0548 a.u. These 
TABLE 3: Selected molecular parameters of $\mathrm{C}_{15} \mathrm{H}_{10} \mathrm{~N}_{2} \mathrm{O}_{3}$.

\begin{tabular}{|c|c|c|c|}
\hline & XRD & DFT & HF \\
\hline \multicolumn{4}{|l|}{ Bond lengths $(\AA)$} \\
\hline N1-N2 & $1.381(2)$ & 1.3716 & 1.359 \\
\hline $\mathrm{C} 8-\mathrm{N} 1$ & $1.397(3)$ & 1.4184 & 1.3968 \\
\hline C7-N1 & $1.402(3)$ & 1.4184 & 1.3973 \\
\hline $\mathrm{C} 9-\mathrm{O} 3$ & $1.225(2)$ & 1.2201 & 1.194 \\
\hline $\mathrm{C} 9-\mathrm{N} 2$ & $1.354(3)$ & 1.3971 & 1.3799 \\
\hline $\mathrm{C} 7-\mathrm{O} 1$ & $1.195(2)$ & 1.2101 & 1.1838 \\
\hline $\mathrm{C} 5-\mathrm{C} 6$ & $1.371(3)$ & 1.3888 & 1.3785 \\
\hline C1-C6 & $1.379(3)$ & 1.3995 & 1.383 \\
\hline C6-C7 & $1.486(3)$ & 1.4913 & 1.4912 \\
\hline $\mathrm{C} 10-\mathrm{C} 11$ & $1.374(3)$ & 1.4038 & 1.3912 \\
\hline $\mathrm{C} 10-\mathrm{C} 15$ & $1.389(3)$ & 1.4028 & 1.3912 \\
\hline C9-C10 & $1.486(3)$ & 1.4955 & 1.4949 \\
\hline $\mathrm{C} 1-\mathrm{C} 2$ & $1.382(3)$ & 1.389 & 1.3787 \\
\hline $\mathrm{C} 1-\mathrm{C} 8$ & $1.480(3)$ & 1.4889 & 1.4889 \\
\hline $\mathrm{C} 8-\mathrm{O} 2$ & $1.202(3)$ & 1.2117 & 1.1854 \\
\hline $\mathrm{C} 4-\mathrm{C} 5$ & $1.385(3)$ & 1.4019 & 1.3913 \\
\hline $\mathrm{C} 2-\mathrm{C} 3$ & $1.388(4)$ & 1.4019 & 1.3912 \\
\hline $\mathrm{C} 3-\mathrm{C} 4$ & $1.367(4)$ & 1.4024 & 1.3923 \\
\hline $\mathrm{C} 12-\mathrm{C} 13$ & $1.373(4)$ & 1.3976 & 1.3866 \\
\hline \multicolumn{4}{|l|}{ Bond angle $\left({ }^{\circ}\right)$} \\
\hline N2-N1-C8 & $123.27(18)$ & 122.915 & 122.7014 \\
\hline N2-N1-C7 & $123.00(17)$ & 122.5233 & 122.2112 \\
\hline C8-N1-C7 & $113.62(17)$ & 112.7771 & 113.1504 \\
\hline C9-N2-N1 & $119.45(18)$ & 118.2369 & 117.9273 \\
\hline C5-C6-C1 & $121.4(2)$ & 121.4357 & 121.6391 \\
\hline O1-C7-N1 & $125.0(2)$ & 125.6323 & 125.962 \\
\hline O1-C7-C6 & $131.0(2)$ & 129.8207 & 129.4085 \\
\hline N1-C7-C6 & $104.01(17)$ & 104.542 & 104.6243 \\
\hline $\mathrm{O} 3-\mathrm{C} 9-\mathrm{N} 2$ & $121.3(2)$ & 121.3245 & 121.529 \\
\hline O3-C9-C10 & $123.18(19)$ & 123.7278 & 123.3337 \\
\hline N2-C9-C10 & $115.51(19)$ & 114.9366 & 115.1286 \\
\hline C6-C1-C8 & 108.91(18) & 108.7184 & 108.4288 \\
\hline $\mathrm{O} 2-\mathrm{C} 8-\mathrm{N} 1$ & $125.0(2)$ & 124.8665 & 125.1344 \\
\hline $\mathrm{O} 2-\mathrm{C} 8-\mathrm{C} 1$ & $130.6(2)$ & 130.2991 & 129.9333 \\
\hline N1-C8-C1 & $104.45(18)$ & 104.8099 & 104.9055 \\
\hline \multicolumn{4}{|l|}{ Torsion angle $\left({ }^{\circ}\right)$} \\
\hline C8-N1-N2-C9 & $-91.2(3)$ & -74.3417 & -72.6382 \\
\hline C7-N1-N2-C9 & $84.7(3)$ & 89.3365 & 90.4325 \\
\hline O1-C7-N1-N2 & $3.4(3)$ & 11.5618 & 11.8452 \\
\hline O1-C7-N1-C8 & $179.7(2)$ & 176.7365 & 176.3893 \\
\hline C6-C7-N1-N2 & $-176.97(18)$ & -169.1879 & -168.9236 \\
\hline O3-C9-N2-N1 & $0.5(3)$ & -6.5549 & -6.4589 \\
\hline C10-C9-N2-N1 & $179.68(18)$ & 174.6203 & 174.5823 \\
\hline $\mathrm{O} 2-\mathrm{C} 8-\mathrm{N} 1-\mathrm{N} 2$ & $-1.6(3)$ & -12.4385 & -12.8859 \\
\hline $\mathrm{O} 2-\mathrm{C} 8-\mathrm{N} 1-\mathrm{C} 7$ & $-177.9(2)$ & -177.5464 & -177.3435 \\
\hline C1-C8-N1-N2 & $177.86(18)$ & 169.2046 & 168.8411 \\
\hline
\end{tabular}

values give information where the molecule tends to have hydrogen bond interactions. The obtained MEP results would help in understanding intermolecular hydrogen bond N2$\mathrm{H} 2 \mathrm{~A} \cdots \mathrm{O} 3$ which is obtained from $\mathrm{X}$-ray analysis.
TABLE 4: Comparison of the experimental and calculated vibrational frequencies $\left(\mathrm{cm}^{-1}\right)$.

\begin{tabular}{lccc}
\hline Assignments & Experiment & DFT & HF \\
\hline$\nu(\mathrm{N}-\mathrm{H})$ & 3350 & 3460 & 3462 \\
$\nu(\mathrm{C}-\mathrm{H})$ of $\mathrm{R}_{3}$ & 3100 & 3098 & 3038 \\
$\nu_{\text {as }}(\mathrm{C}-\mathrm{H})$ of $\mathrm{R}_{1}$ & 3010 & 3061 & 3011 \\
$\nu_{\mathrm{s}}(\mathrm{C}=\mathrm{O})$ of $\mathrm{R}_{2}$ & 1790 & 1778 & 1843 \\
$\nu_{\text {as }}(\mathrm{C}=\mathrm{O})$ of $\mathrm{R}_{2}$ & 1749 & 1734 & 1788 \\
$\nu(\mathrm{C}=\mathrm{O})$ & 1716 & 1698 & 1750 \\
$\nu_{\text {as }}(\mathrm{C}=\mathrm{C})$ of $\mathrm{R}_{3}$ & 1640 & 1593 & 1600 \\
$\nu_{\text {as }}(\mathrm{C}=\mathrm{C})$ of $\mathrm{R}_{1}$ & 1601 & 1568 & 1583 \\
$\gamma(\mathrm{N}-\mathrm{H})$ & $1488-1530$ & 1480 & 1509 \\
$\nu(\mathrm{N}-\mathrm{N})$ & 1384 & 1373 & 1433 \\
$\nu(\mathrm{C}-\mathrm{C})+(\mathrm{N}-\mathrm{H})$ & 1284 & 1225 & 1244 \\
$\nu(\mathrm{C}-\mathrm{N})$ of $\mathrm{R}_{2}$ & 1121 & 1083 & 1127 \\
$\omega(\mathrm{N}-\mathrm{H})$ & 879 & 872 & 880 \\
$\omega(\mathrm{C}-\mathrm{H})$ of $\mathrm{R}_{3}$ & 703 & 689 & 720 \\
$\omega(\mathrm{C}-\mathrm{H})$ of $\mathrm{R}_{1}$ & 691 & 697 & 717 \\
\hline
\end{tabular}

Note: $\nu$, stretching; $\gamma$, rocking; $\omega$, wagging; s, symmetric; as, asymmetric; $\mathrm{R}$, ring.

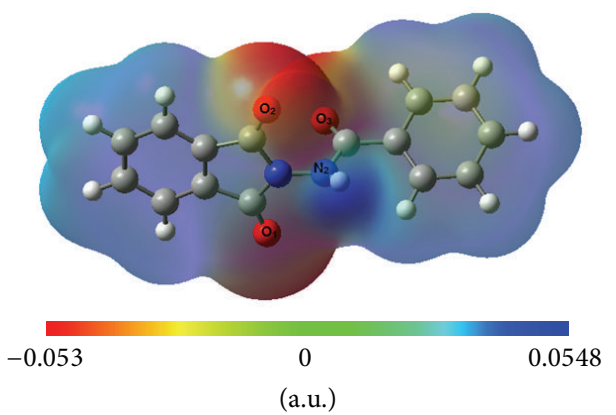

FIGURE 3: Molecular electrostatic map for molecular compound, $\mathrm{C}_{15} \mathrm{H}_{10} \mathrm{~N}_{2} \mathrm{O}_{3}$, calculated at B3LYP/6-31G+(d) level.

3.5. Scanning Electron Micrography (SEM). Surface morphology of the grown crystal, $N$-(1,3-dioxoisoindolin-2yl)benzamide, was investigated by scanning electron microscope. SEM measurements were performed at FEI-Quanta FEG 250. The surface morphology and particle size of the title compound, $\mathrm{C}_{15} \mathrm{H}_{10} \mathrm{~N}_{2} \mathrm{O}_{3}$, have been shown in Figure 4. From the SEM micrographs, it can be seen that particles have nonuniform distribution. The structural morphology consists of foamlike shape. SEM images were taken 20000x and 5000x magnifications with acceleration voltage of $3-4 \mathrm{kV}$.

3.6. IR Spectra. The experimental FTIR spectra were collected by using $\mathrm{KBr}$ Pellets on Schmadzu 8900 FT-IR spectrophotometer and shown in Figure 5. Obtained frequencies were recorded in wave number $\mathrm{cm}^{-1}$. In this section of the study, vibrational frequencies calculated at B3YLP/6-31+G(d) and $H F / 6-31+G(d)$ levels and scaled by 0.9613 and 0.8929 , respectively $[29,30]$. As seen from Table 4 , calculated and experimental values are in good agreement to each other. The broadest absorption was observed at $3350 \mathrm{~cm}^{-1}$ due to 


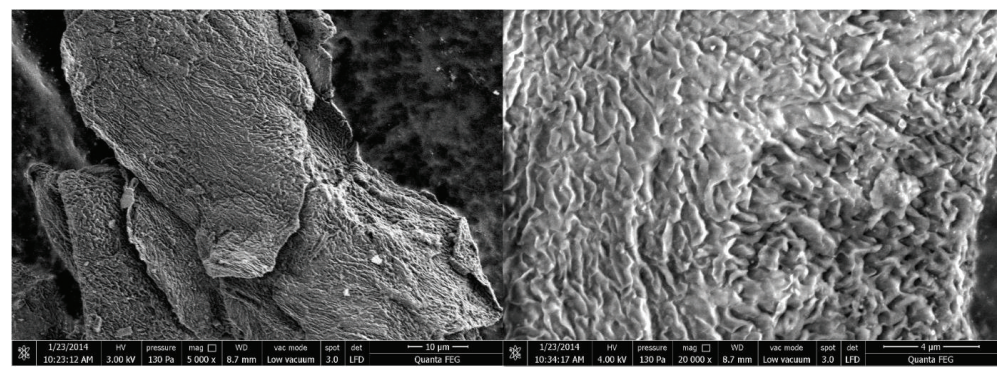

Figure 4: SEM images of $\mathrm{C}_{15} \mathrm{H}_{10} \mathrm{~N}_{2} \mathrm{O}_{3}$.

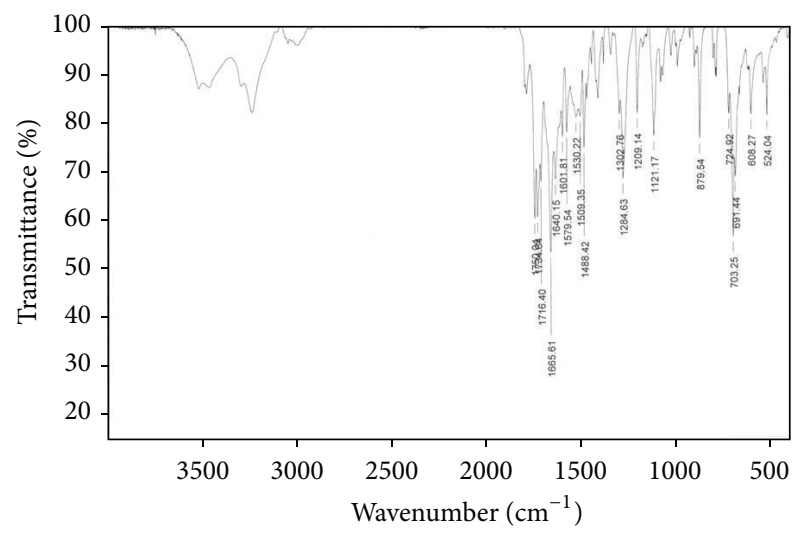

Figure 5: IR spectra of $\mathrm{C}_{15} \mathrm{H}_{10} \mathrm{~N}_{2} \mathrm{O}_{3}$.

the N-H stretching of bridged moiety. Theoretically this band calculated at $3460 \mathrm{~cm}^{-1}$ and $3462 \mathrm{~cm}^{-1}$ for B3YLP and HF methods, respectively. $\mathrm{N}-\mathrm{H}$ stretching vibration was observed at $2500-3500 \mathrm{~cm}^{-1}$ band range with related structure [31]. Aromatic rings have the $\mathrm{C}-\mathrm{H}$ stretching vibrations assigned to $3100-3000 \mathrm{~cm}^{-1}$ [32]. For the title molecule, C-H stretching vibration was observed at $3100 \mathrm{~cm}^{-1}$ while theoretical values have been calculated at $3098 \mathrm{~cm}^{-1}$ for B3YLP/6$31+\mathrm{G}(\mathrm{d})$ and $3038 \mathrm{~cm}^{-1}$ for $\mathrm{HF} / 6-31+\mathrm{G}(\mathrm{d})$ methods. For the title compound, $\mathrm{C}=\mathrm{O}$ symmetric stretching mode and asymmetric stretching mode were observed at $1790 \mathrm{~cm}^{-1}$ and $1749 \mathrm{~cm}^{-1}$ for dioxoisoindolin group, respectively. All these experimental vibrational assignments are in agreement with related compound [33]. Calculated values of the $\mathrm{C}=\mathrm{O}$ symmetric stretching mode were $1778 \mathrm{~cm}^{-1}$ and $1843 \mathrm{~cm}^{-1}$ for B3YLP and HF, respectively. These asymmetric stretching frequencies were computed at $1734 \mathrm{~cm}^{-1}$ and $1788 \mathrm{~cm}^{-1}$ for B3YLP and HF, respectively. $\mathrm{C}=\mathrm{O}$ vibration of the amide group was observed at $1716 \mathrm{~cm}^{-1}$ experimentally. Presence of these spectroscopic values ( $\mathrm{N}-\mathrm{H}$ and $\mathrm{C}=\mathrm{O}$ vibrations) shows that the title molecule has ketoamine tautomeric form [34, 35]. The details of the spectral values are shown in Table 4.

\section{Conclusions}

In this paper we have investigated the molecular structure of $N$-(1,3-dioxoisoindolin-2yl)benzamide, using single crystal X-ray diffraction, IR spectroscopy, and computational methods. The results obtained show that the X-ray crystal structure and computational methods are consistent with each other. There was particularly good agreement using the DFT (B3LYP) with the $6-31+G(d)$ basis set. The structural $\mathrm{X}$-ray analysis has indicated that the crystal structure is stabilized by $\mathrm{N}-\mathrm{H} \cdots \mathrm{O}$ hydrogen bonding. These results were consistent with those obtained by a MEP analysis. The calculated and observed $\mathrm{N}-\mathrm{H}$ and $\mathrm{C}=\mathrm{O}$ vibrations in the IR spectrum confirm the ketoamine tautomeric form of the structure. The surface morphology was also studied by SEM analysis and the results indicate a nonuniform distribution for the sample.

\section{Conflict of Interests}

The authors declare that there is no conflict of interests regarding the publication of this paper.

\section{References}

[1] B. K. Revathi, D. Reuben Jonathan, S. Sathya, K. Prathebha, and G. Usha, "Crystal structure of 4-methyl- $N$-[2-(piperidin-1yl)ethyl]benzamide monohydrate," Acta Crystallographica Section E Crystallographic Communications, vol. 71, no. 5, pp. o359o360, 2015.

[2] S. A. Prabhu, M. Suresh, A. A. Jameel, M. S. A. Padusha, and B. Gunasekaran, "Crystal structure of N-[(morpholin-4-yl)(thiophen-2-yl)methyl]benzamide," Acta Crystallographica E, vol. 71, pp. o498-o499, 2015.

[3] J. J. Novina, G. Vasuki, A. Baheti, and K. R. J. Thomas, "N(4,4'-Dibromo-[1,1'-biphenyl]-2-yl)benzamide," Acta Crystallographica Section E: Structure Reports Online, vol. 69, no. 2, article $0222,2013$.

[4] K. Chowdhury, R. Mukhopadhyay, M. Mukherjee, C. K. Broder, and G. Kundu, " $(Z)$-3-Acetonylidene-2,3-dihydro- $1 H$ isoindolin-1-one," Acta Crystallographica Section E, vol. 57, pp. o421-o423, 2001.

[5] I. Pendrak, S. Barney, R. Wittrock, D. M. Lambert, and W. D. Kingsbury, "Synthesis and anti-HSV activity of a-ring-deleted mappicine ketone analog," Journal of Organic Chemistry, vol. 59, no. 9, pp. 2623-2625, 1994.

[6] E. C. Taylor, P. Zhou, L. D. Jennings, Z. Mao, B. Hu, and J.-G. Jun, "Novel synthesis of a conformationally-constrained analog of DDATHF," Tetrahedron Letters, vol. 38, no. 4, pp. 521-524, 1997.

[7] G. Pandey, R. Varkhedkar, and D. Tiwari, "Efficient access to enantiopure 1,3-disubstituted isoindolines from selective catalytic fragmentation of an original desymmetrized rigid 
overbred template," Organic \& Biomolecular Chemistry, vol. 13, no. 15, pp. 4438-4448, 2015.

[8] STOE \& Cie, X-AREA (Version 1.18) and X-RED32 (Version 1.04), STOE \& Cie, Darmstadt, Germany, 2002.

[9] G. M. Sheldrick, "A short history of SHELX," Acta Crystallographica Section A, vol. 64, no. 1, pp. 112-122, 2008.

[10] L. J. Farrugia, "ORTEP-3 for windows-a version of ORTEPIII with a Graphical User Interface (GUI)," Journal of Applied Crystallography, vol. 30, no. 1, p. 565, 1997.

[11] L. J. Farrugia, “WinGX suite for small-molecule single-crystal crystallography," Journal of Applied Crystallography, vol. 32, no. 4, pp. 837-838, 1999.

[12] S. K. Mohamed, M. A. Farrukh, M. Akkurt, M. R. Albayati, and A. A. Abdelhamid, "2-(1,3-Dioxoisoindolin-2-yl)acetic acid$N^{\prime}$-[(E)-2-methoxybenzylidene]pyridine-4-carbohydrazide (1/1)," Acta Crystallographica E, vol. 68, p. o2442, 2012.

[13] M. H. Bhatti, U. Yunus, S. Saeed, S. R. Shah, and W.-T. Wong, "The 1:1 adduct of caffeine and 2-(1,3-dioxoisoindolin2-yl)acetic acid," Acta Crystallographica Section E, vol. 67, no. 9, Article ID o2240, 2011.

[14] W. Sripet, S. Chantrapromma, P. Ruanwas, and H.-K. Fun, "4-Bromo-N-(4-meth-oxy-2-nitro-phen-yl)benzamide," Acta Crystallographica Section E: Structure Reports Online, vol. 68, no. 4, Article ID o1234, 2012.

[15] J. Bernstein, R. E. Davies, L. Shimoni, and N.-L. Chang, "Patterns in hydrogen bonding: functionality and graph set analysis in crystals," Angewandte Chemie, vol. 34, no. 15, pp. 1555-1573, 1995.

[16] A. D. Becke, "Density-functional thermochemistry. III. The role of exact exchange," The Journal of Chemical Physics, vol. 98, no. 7, pp. 5648-5652, 1993.

[17] C. Lee, W. Yang, and R. G. Parr, "Development of the ColleSalvetti correlation-energy formula into a functional of the electron density," Physical Review B, vol. 37, no. 2, pp. 785-789, 1998.

[18] H. B. Schlegel, "Optimization of equilibrium geometries and transition structures," Journal of Computational Chemistry, vol. 3, no. 2, pp. 214-218, 1982.

[19] C. Peng, P. Y. Ayala, H. B. Schlegel, and M. J. Frisch, "Using redundant internal coordinates to optimize equilibrium geometries and transition states," Journal of Computational Chemistry, vol. 17, no. 1, pp. 49-56, 1996.

[20] M. J. Frisch, G. W. Trucks, H. B. Schlegel et al., Gaussian 03, Revision E.01, Gaussian, Wallingford, Conn, USA, 2004.

[21] R. Dennington, T. Keith, and J. Millam, GaussView, Version 4.1, Semichem, Shawnee Mission, Kan, USA, 2007.

[22] B. Gonzales, P. Lorenzo-Luis, A. Romerosa, M. SerranoRuiz, and P. Gili, "Theoretical aspects on water soluble $\left[\mathrm{RuClCp}\left(\mathrm{PPh}_{3}\right)_{2}\right], \quad\left[\mathrm{RuClCp}(\mathrm{PTA})\left(\mathrm{PPh}_{3}\right)\right], \quad\left[\mathrm{RuClCp}(\mathrm{PTA})_{2}\right]$, $[\mathrm{RuClCp}(\mathrm{mPTA})(\mathrm{PPh} 3)]^{+}$and $\left[\operatorname{RuClCp}(\mathrm{mPTA})_{2}\right]^{2+}(\mathrm{PTA}=$ 1,3,5-triaza-7-phosphaadamantane; mPTA $=N$-methyl-1,3,5triaza-7-phosphaadamantane)," Journal of Molecular Structure: THEOCHEM, vol. 894, pp. 59-63, 2009.

[23] P. D. S. Babu, S. Periandy, S. Mohan, S. Ramalingam, and B. G. Jayaprakash, "Molecular structure and vibrational investigation of benzenesulfonic acid methyl ester using DFT (LSDA, B3LYP, B3PW91 and MPW1PW91) theory calculations," Spectrochimica Acta-Part A: Molecular and Biomolecular Spectroscopy, vol. 78, no. 1, pp. 168-178, 2011.

[24] P. Politzer and J. S. Murray, "The fundamental nature and role of the electrostatic potential in atoms and molecules," Theoretical Chemistry Accounts, vol. 108, no. 3, pp. 134-142, 2002.
[25] E. Scrocco and J. Tomasi, "Electronic molecular structure, reactivity and intermolecular forces: an euristic interpretation by means of electrostatic molecular potentials," in Advances in Quantum Chemistry, vol. 11, pp. 115-121, Elsevier, 1978.

[26] F. J. Luque, J. M. Lopez, and M. Orozco, "Perspective on 'Electrostatic interactions of a solute with a continuum. A direct utilization of $\mathrm{ab}$ initio molecular potentials for the prevision of solvent effects," Theoretical Chemistry Accounts, vol. 103, pp. 343-345, 2000.

[27] H. Tanak, F. Erşahin, Y. Köysal, E. Ağar, Ş. Işik, and M. Yavuz, "Theoretical modeling and experimental studies on Nn-Decyl-2-oxo-5-nitro-1-benzylidene-methylamine," Journal of Molecular Modeling, vol. 15, no. 10, pp. 1281-1290, 2009.

[28] H. Saraçoğlu, Ö. Sarı̈̈z, and S. Öznergiz, "Quantum chemical, spectroscopic, and X-ray diffraction studies of N-diphenylphosphino-4-methylpiperidine selenide (1)," Molecular Crystals and Liquid Crystals, vol. 591, no. 1, pp. 47-63, 2014.

[29] J. B. Foresman and A. Frisch, Exploring Chemistry with Electronic Structure Methods, Gaussian Inc, Pittsburgh, Pa, USA, 2nd edition, 1996.

[30] J. P. Merrick, D. Moran, and L. Radom, "An evaluation of harmonic vibrational frequency scale factors," Journal of Physical Chemistry A, vol. 111, no. 45, pp. 11683-11700, 2007.

[31] Ç. Yüksektepe, N. Çalişkan, M. Genç, and S. Servi, "Synthesis, crystal structure, HF and DFT calculations of 1-(2-chlorobenzyl)-N-(1-(2-chlorobenzyl)-4,5-dihydro-1H-imidazol-2-yl)-1Hbenzimidazol-2-amine," Crystallography Reports, vol. 55, no. 7, pp. 1188-1193, 2010.

[32] K. Sarojini, H. Krishnan, C. C. Kanakam, and S. Muthu, "Synthesis, structural, spectroscopic studies, NBO analysis, NLO and HOMO-LUMO of 4-methyl-N-(3-nitrophenyl)benzene sulfonamide with experimental and theoretical approaches," Spectrochimica Acta Part A: Molecular and Biomolecular Spectroscopy, vol. 108, pp. 159-170, 2013.

[33] K. Faghıhı, M. Absalar, and M. Hajıbeyg1, "Synthesis and characterization of new optically active polyamides containing 2-(4-nitro-1,3-dioxoisoindolin-2-yl)succinic acid and aromatic diamines via direct polycondensation," Turkish Journal of Chemistry, vol. 34, pp. 81-90, 2010.

[34] A. Elmalı, M. Kabak, E. Kavlakoglu, Y. Elerman, and T. N. Durlu, "Tautomeric properties, conformations and structure of N-(2-hydroxy-5-chlorophenyl) salicylaldimine," Journal of Molecular Structure, vol. 510, no. 1-3, pp. 207-214, 2000.

[35] S. R. Salman and N. A. I. Saleh, "Infra-red study of tautomerism in some schiff bases," Spectroscopy Letters, vol. 30, no. 7, pp. 1289-1300, 1997. 

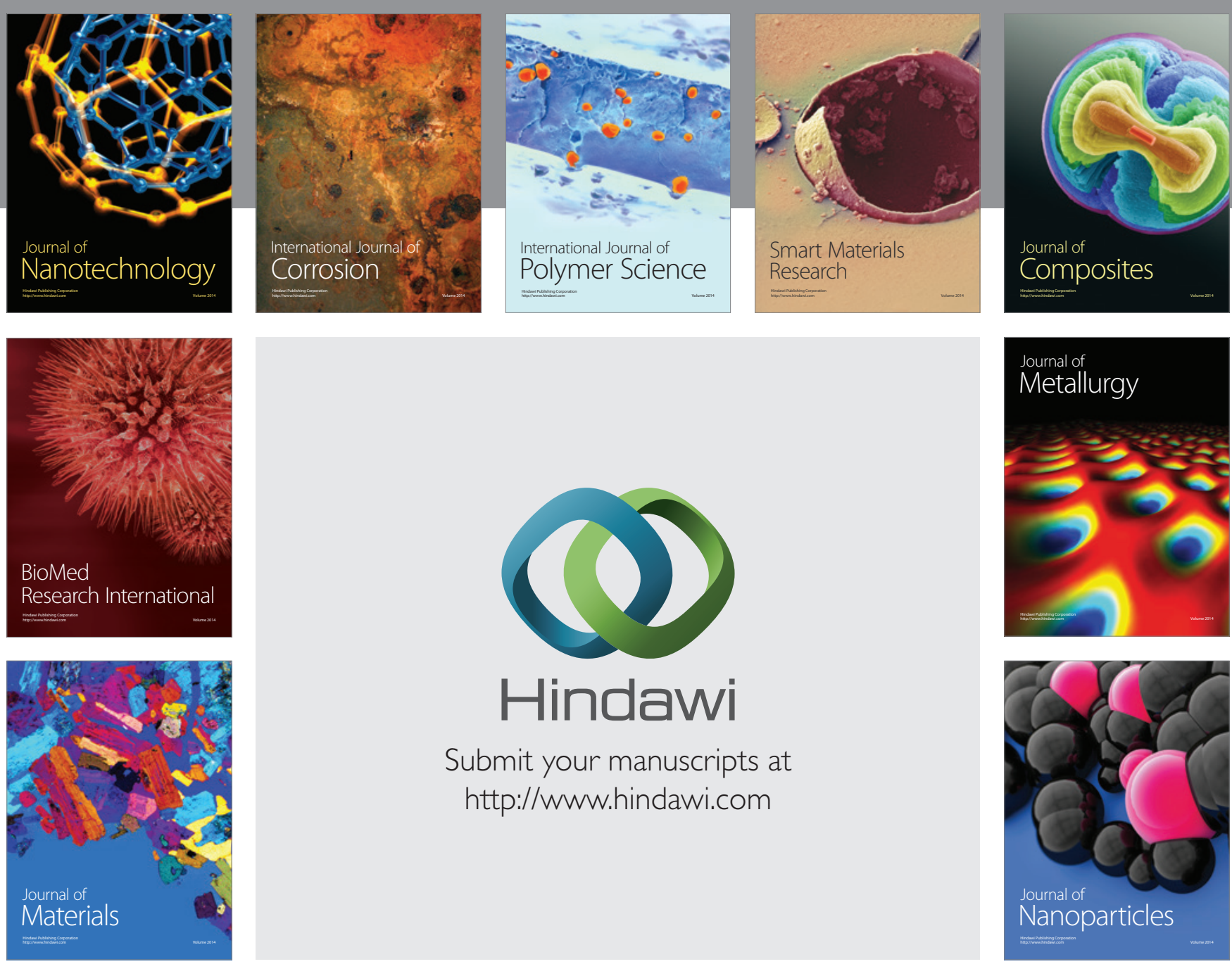

Submit your manuscripts at http://www.hindawi.com
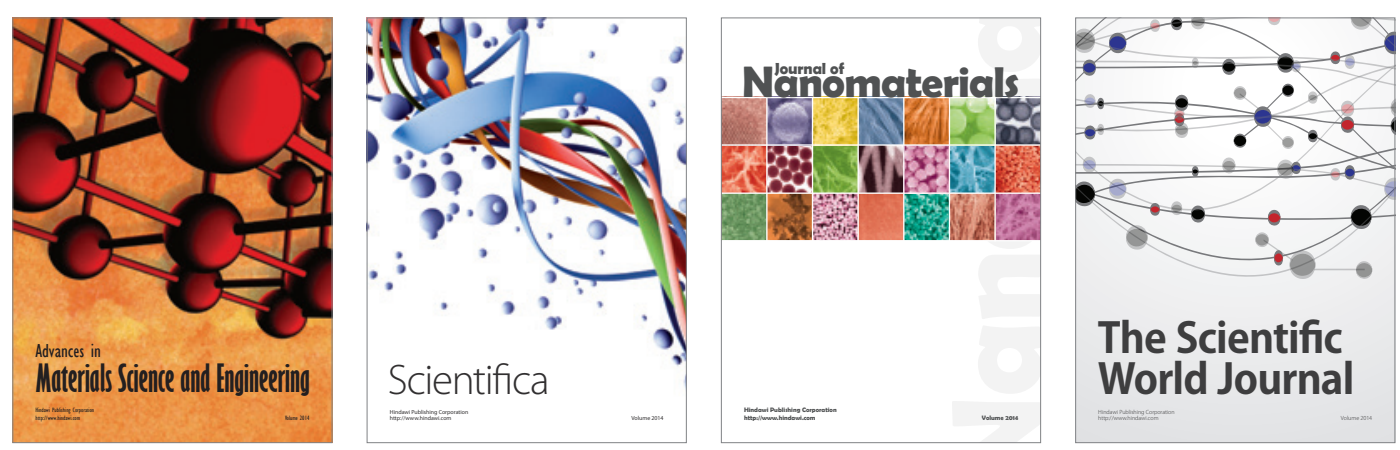

\section{The Scientific World Journal}
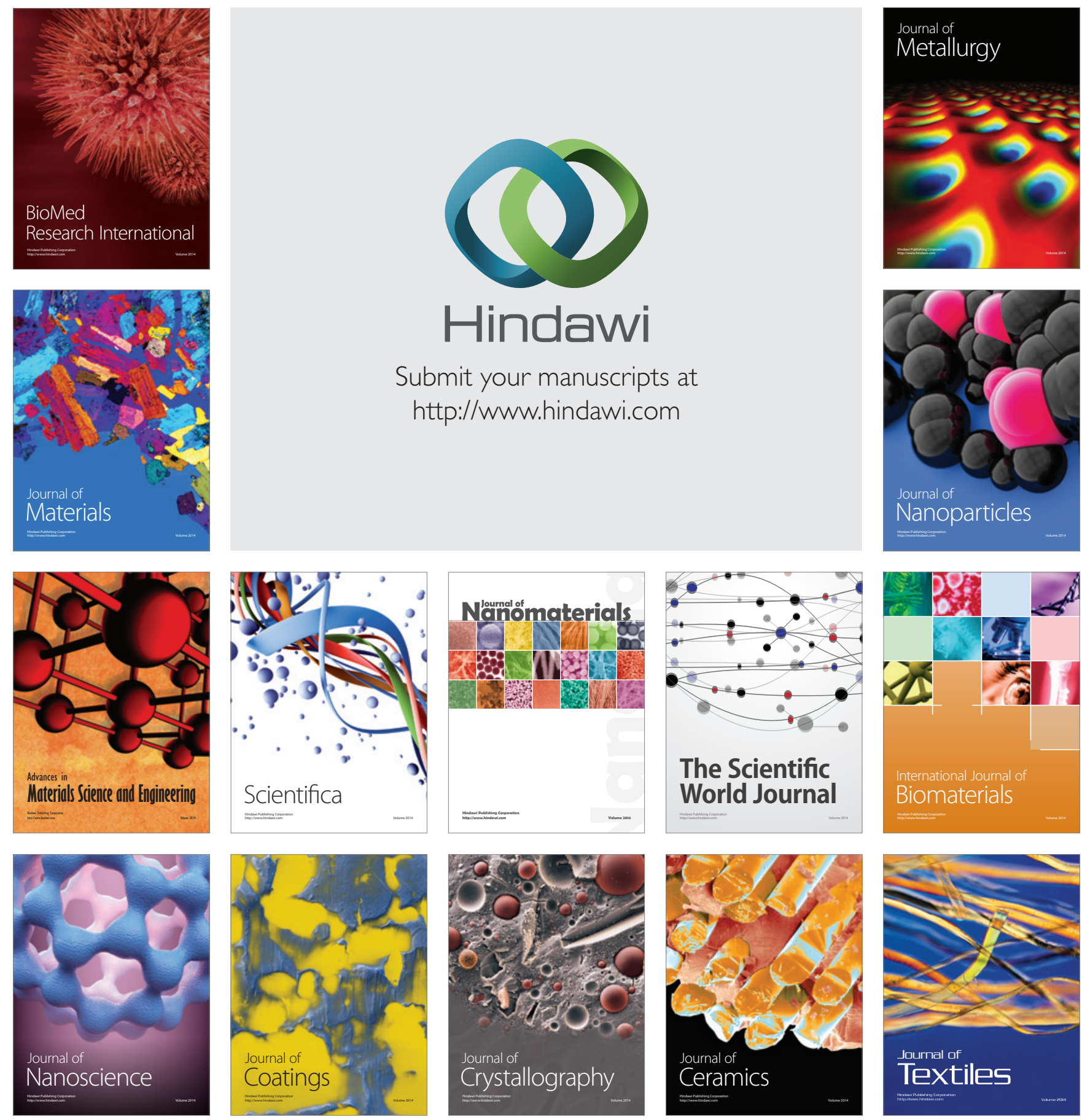